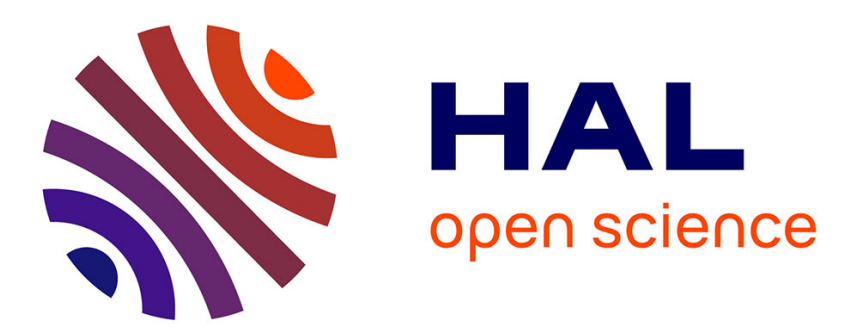

\title{
Structural characteristics of Bi-based superconductors studied by positron annihilation
}

\author{
S. Wang, Z. Tang, X. Gao, Z. Zhao
}

\section{To cite this version:}

S. Wang, Z. Tang, X. Gao, Z. Zhao. Structural characteristics of Bi-based superconductors studied by positron annihilation. Journal de Physique IV Proceedings, 1993, 03 (C4), pp.C4-213-C4-215. 10.1051/jp4:1993431 . jpa-00251474

\section{HAL Id: jpa-00251474 https://hal.science/jpa-00251474}

Submitted on 1 Jan 1993

HAL is a multi-disciplinary open access archive for the deposit and dissemination of scientific research documents, whether they are published or not. The documents may come from teaching and research institutions in France or abroad, or from public or private research centers.
L'archive ouverte pluridisciplinaire HAL, est destinée au dépôt et à la diffusion de documents scientifiques de niveau recherche, publiés ou non, émanant des établissements d'enseignement et de recherche français ou étrangers, des laboratoires publics ou privés. 


\title{
Structural characteristics of Bi-based superconductors studied by positron annihilation
}

\author{
S.J. WANG, Z. TANG, X.H. GAO* and Z.X. ZHAO**
}

Department of Physics, Wuhan University, Wuhan 430072, P.R. of China

* Department of Chemistry, Central-South University of Technology, Changsha 410083, P.R. of China

** Institute of Physics, Chinese Academy of Sciences, Beijing, 100080, P.R. of China

\begin{abstract}
We have measured the positron lifetime spectra as a function of temperature from 80 to $300 \mathrm{~K}$ and Doppler-broadening annihilation radiation (DBAR) spectra in normal and superconducting states for three kinds of Bi-based superconductors: Bi2212, Pband $\mathrm{F}$-doped Bi2223. For $\mathrm{Pb}$-doped Bi2223 superconductor, anomalies in the temperature dependence of positron lifetimes indicate the structural instabilities. However, a continuous increasing in the mean lifetime is observed for F-doped Bi2223 system and interpreted in terins of a simple thermal expansion with an average linear expansion coefficient a $-35 * 10^{-6}$. The difference spectra of DBAR spectra after deconvolution between two states show an evidence for charge transfer between the $\mathrm{Cu}-\mathrm{O}$ and $\mathrm{Bi}-\mathrm{O}$ planes in Bi-based superconductorg. The role of oxygen defects in charge transfer was discussed.
\end{abstract}

\section{INTRODUCTION}

The electronic structure of high-Tc superconductors has been a subject of intense study since their discovery. Elements substitution in cuprate superconductors is a very useful method to change its structural characteristics. Positron annihilation spectroscopy is an established experimental method for an electronic structure and defect study of solids. In this study, we have prepared three kinds of polycrystalline Bi-based samples doped in Bi-O layers, measured positron lifetime spectra as a function of temperature from 80 to $300 \mathrm{~K}$ and DBAR spectra in normal and superconducting states for these samples and clarify the origin of the temperature dependence of positron annihilation parameters.

\section{EXPFRTMENT}

The samples used in the experiments were prepared by the solid state reaction method[1], and were characterized by means of powder x-ray diffraction. The transition temperature $\mathrm{Tc}$ of the $\mathrm{Bi} 2212, \mathrm{Bi}(\mathrm{Pb}) 2223, \mathrm{~F}$-doped $\mathrm{Bi}(\mathrm{Pb}) 2223$ were determined to be $89 \mathrm{~K}, 109.6 \mathrm{~K}$ and $118 \mathrm{~K}$ respectively by the resistivity measurements.

Positron lifetime measurements were carried out using a fast-fast coincidence spectrometer with timing resolution of $240 \mathrm{ps}$. Each spectrum contained one million counts and was analyzed using the PATFIT program. DBAR spectra were measured by using a coaxial HPGe detector with a resolution (FWHM) of $1.5 \mathrm{Kev}$ at $514 \mathrm{Kev}$ line of ${ }^{85} \mathrm{Sr}$. The Total number of counts collected for each spectrum was five millions, 
and was analyzed by applying a point by point deconvolution process[2] to eliminate the affection of instrumental resolution. In order to study the changes of electronic structure, the difference spectra after deconvolution between nomal and superconducting states were took.

\section{RESULTS AND DISCUSSION}

1.Structural instability

All the positron lifetime spectra were best fitted to two exponential components. The long-lived component iq can be attributed to positron annihilation in the lower electron density region, e.g., defects. $\tau_{2}$ as a function of temperature from 80 to $300 \mathrm{~K}$ for the $\mathrm{Bi}(\mathrm{Pb}) 2223$ and the $\mathrm{F}$-doped $\mathrm{Bi}(\mathrm{Pb}) 2223$ are shown in Fig.1,2. The variations in the lifetime for $B i 2212$ are more irregular than those for $B i(\mathrm{~Pb}) 2223$ and $\mathrm{F}$-doped $\mathrm{Bi}(\mathrm{Pb}) 2223$. From Fig.1, we can see that, the positron lifetime results display three narrow valleys near $120,140,160 \mathrm{~K}$ and two wide valleys near 240 and 270K. McMullen et al. [3] has calculated the positron density distribution (PDD) in the Bi2212 system. The results show that the PDD is greatest between the Bi-O layers and the oxygen defects cannot bind positrons. The anomalies in the lifetime indicate the structural instabilities of the $\mathrm{Bi}(\mathrm{Pb}) 2223$ in normal state, which may be caused by structural changes, such as the softening of the lattice, or the motion of vacancies in $\mathrm{Bi}-\mathrm{O}$ layers[4]. However, we don't observe any anomaly fron Fig.2, this fact suggests that adding $\mathrm{F}$ impurities can stabilized $\mathrm{Bi}-\mathrm{O}$ layers in the $\mathrm{Bi}(\mathrm{Pb}) 2223$ system.

2. Thermal expansion

The temperature variations of $\tau_{\mathrm{y}}$ for the $\mathrm{F}$-doped $\mathrm{Bi}(\mathrm{Pb}) 2223$ are shown in Fig. 3 . From Fig. 3, it can be seen that $\tau_{\mathrm{f}}$ increases continuously from 212 ps to 217 ps. This temperature dependence can be understood in terms of a simple thermal

expansion which should result in a longer $\tau_{\mathbb{R}}$ while the temperature increases. Therefore, we can write

$$
\begin{aligned}
& \lambda(T)=\lambda\left(T_{0}\right)\left[1+\alpha\left(T-T_{0}\right)\right]^{-1 / 3} \\
& {\left[\tau(T) / \tau\left(T_{0}\right)\right]^{1 / 3}-1=\alpha\left(T-T_{0}\right)}
\end{aligned}
$$

where $T_{0}$ is a reference temperature and $a$ is the coefficient of the average linear thermal expansion for the $\mathrm{F}$-doped $\mathrm{Bi}(\mathrm{Pb}) 2223$.

A value of $-35 * 10^{-6}$ can be evaluated by the weighted least-squares fit which is agree with recent reported value of $a-23-27 * 10^{-6}$ for c-axis by neutron diffraction method[5].

3. Evidence for charge transfer

The difference spectra for the $\mathrm{Pb}$ - and $\mathrm{F}$-doped $\mathrm{Bi} 2223$ after deconvolution is shown in Fig.4, the difference spectrum for Bi2212 is the same as that for the $\mathrm{Bi}(\mathrm{Pb}) 2223$. Fig. 4 shows that the density of high momentum electrons in the $\mathrm{Bi}-\mathrm{O}$ layers increases at superconducting state. From the variation in positron lifetime parameter, we don't observe any evidence for shallow trap in the Bi-based system. In the charge transfer model, when the sample is cooled to $\mathrm{S}$ state, the electron from $\mathrm{Cu}$ in the $\mathrm{Cu}-\mathrm{O}$ layer may be transferred to vacancies in the Bi-O layerg where the electrons generally have much lower momentum, and carriers are created in the Cu-O plane[5], which will result in the increasing density of high momentum 
electrons in the Bi-O layers. Since $F$ atom substitute the oxygen atom and doping $F$ atom can greatly change charge transfer, it can be inferred that oxygen defects play an important role in the charge transfer process.

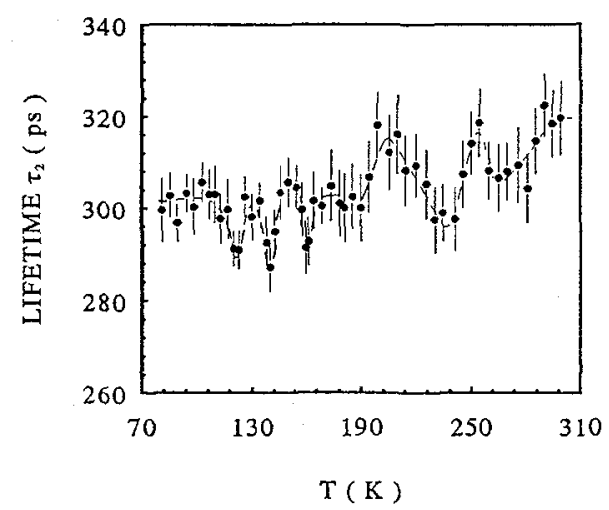

Fig. 1 Positron lifetime $\tau_{2}$ vs. temperature in the $\mathrm{Pb}$-doped $\mathrm{Bi}(\mathrm{Fb}) 2223$

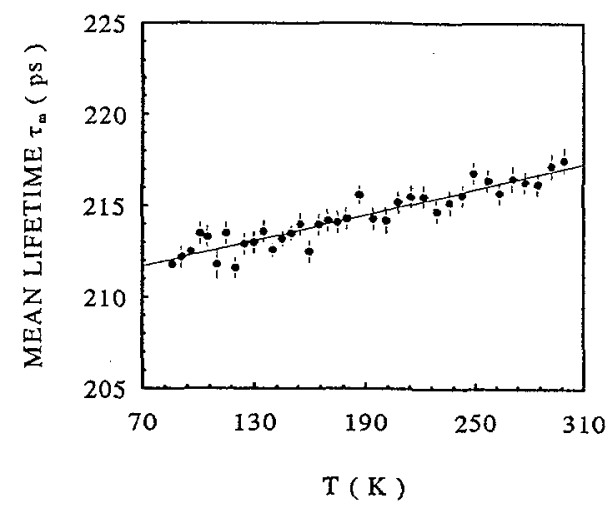

Fig.3 Mean lifetime $\tau_{\text {荇 }}$ vs. temperature in the $\mathrm{F}$-doped $\mathrm{Bi}(\mathrm{Pb}) 2223$

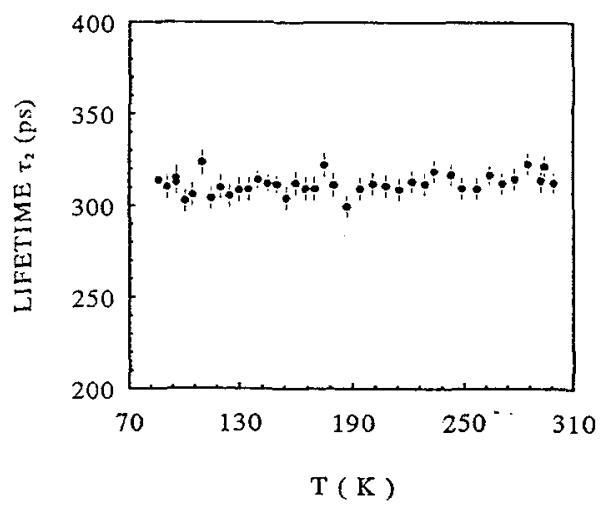

Fig. 2 Positron lifetime $\tau_{:}$vs. temperature in the F-doped Bi2223

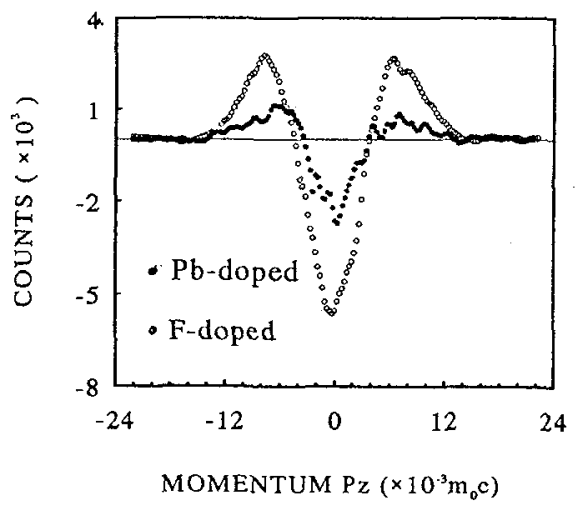

Fig.4 The difference spectra for DBAR spectra (N-S) for the $\mathrm{Pb}$ - and $\mathrm{F}$-doped. $\mathrm{Bi} 2223$

\section{REFERENCE}

/1/ Gao, X.H, et al. Modern Phys.Lett. B6(1992)943

12/ Dannefaer, s, et al. Nucl. Inst. \& Meth. 131(1975)119

/3/ McMullen, T, et al. Phys.Rev.B43(1991)10422

/4/ Tang, $z$, et al. J.Phys.:Condens. Matter $5(1993) 345$

/5/ Arendt, R.H, et al. Physica C 194(1992)397

16/ Jorgensen, J.F, Physios Today, p34, June 1991 